\title{
ERRATUM
}

\section{Authority Contests, Power and Policy Paradigm Change: Explaining Developments in Grain Marketing Policy in Prairie Canada-ERRATUM}

\section{Grace Skogstad and Tanya Whyte}

doi: 10.1017/S0008423914001115, Published by Cambridge University Press, 16 January 2015.

In the article by Skogstad and Whyte (2015) the French abstract was not proofread and corrected for syntax and grammar errors when first published online.

The original has since been corrected both online and in print. We apologise to the author and readers for this oversight.

\section{Reference}

1. Grace Skogstad and Tanya Whyte. 2015. Authority Contests, Power and Policy Paradigm Change: Explaining Developments in Grain Marketing Policy in Prairie Canada. Canadian Journal of Political Science 48 (1). 